\title{
ЭФФЕКТИВНОСТЬ БЕЛКОВ АЛЛОГЕННЫХ ГЕПАТОЦИТОВ В КОРРЕКЦИИ ИММУНОМЕТАБОЛИЧЕСКИХ НАРУШЕНИЙ ПРИ ОСТРОМ ИШЕМИЧЕСКОМ ПОРАЖЕНИИ ПЕЧЕНИ
}

\author{
С Литвинова Е.С., Конопля А.И., Дудка В.Т.
}

\author{
Курский государственный медицинский университет (КГМУ) \\ Россия, 305041, Курская область, г. Курск, ул. К. Маркса, д. 3
}

\begin{abstract}
Цель исследования - определить эффективность культуральной жидкости аллогенных гепатоцитов и выделенных из них белков при коррекции иммунных и метаболических нарушений остро возникшего ишемического поражения печени.

Материалы и методы. Исследование выполнено на 105 половозрелых и здоровых крысах линии Вистар. Острое ишемическое поражение печени (ОИПП) вызывали пережатием гепатодуоденальной связки в течение 20 минут. Выделенные от новорожденных животных аллогенные гепатоциты использовали для приготовления культуральной жидкости, из которой получали белки. Культуральную жидкость аллогенных гепатоцитов (КЖАГ) и их белки вводили с началом моделирования острой ишемии печени пятикратно (с интервалов в 24 часа) внутрибрюшинно крысам с ОИПП по расчету 5 мг/кг белка.

Результаты. Острая ишемия печени вызывает развитие биохимических синдромов поражения печени (цитолиза, внутри- и внепеченочного холестаза, токсического поражения, недостаточности синтетических процессов), активирует процессы перекисного окисления липидов, нарушает внутриэритроцитарный метаболизм, вызывает развитие оксидантного стресса, супрессию формирования адаптивного и врожденного иммунитета. Введение животным с ОИПП КЖАГ, неразделенных белков КЖАГ или белков КЖАГ с молекулярной массой (ММ) менее 130 кДа нормализует или корригирует изученные биохимические и иммунологические параметры. Белки КЖАГ с ММ больше 130 кДа такими эффектами не обладают.
\end{abstract}

Заключение. При анализе корригирующей активности КЖАГ или белков КЖАГ при остро возникшем ишемическом поражении печени на динамику биохимических маркеров, формирование клеточного и гуморального иммунитета, внутриэритроцитарный метаболизм, изменение метаболической и функциональной активности нейтрофилов периферической крови, активирование свободно-радикального окисления, установлена следующая последовательность (по степени увеличения эффективности): отсутствие корригирующего эффекта у белков КЖАГ с ММ более 130 кД, наличие нормализующей и корригирующей активности: КЖАГ - неразделенные белки КЖАГ - белки КЖАГ менее 130 кД.

Ключевые слова: иммунометаболические нарушения; белки культуральной жидкости аллогенных гепатоцитов; остря ишемия печени.

Литвинова Екатерина Сергеевна - канд. мед. наук, доцент кафедры патологической анатомии, КГМУ, г. Курск. E-mail: kat roma@mail.ru (автор, ответственный за переписку)

Конопля Александр Иванович - д-р. мед. наук, профессор, заслуженный деятель науки РФ, зав. кафедрой биологической химии, КГМУ, г. Курск. ORCID iD: 0000-0003-4748-8405. E-mail: konoplya51@mail.ru

Дудка Виктор Тарасович - канд. мед. наук, доцент, зав. кафедрой патологической анатомии, КГМУ, г. Курск. E-mail: dudkaviktor@rambler.ru

В настоящее время проблема диагностики и терапии острых и хронических заболеваний печени продолжает оставаться актуальной в связи со сложностью дифференциальной диагностики и оптимального выбора эффективных патогенетических способов лечения на фоне продолжающегося роста количества пациентов с данной патологией $[1,13,20,26]$.

В клинической практике для бескровных манипуляций на печени нередко используется пережатие печеночно-дуоденальной связки. Однако возникающая при этом ишемия ткани может быть причиной резких нарушений функции печени. Увеличение сроков острой ишемии более чем на 15 минут приводит не только к деструктивным процессам в ткани пе- чени, но и оказывает отрицательное влияние на весь организм в целом [3, 21, 22, 25].

В условиях ишемии печени в первую очередь усиливаются свободно-радикальные процессы и обусловленное ими перекисное окисление липидов (ПОЛ) клеточных мембран. Ускорение образования гидроперекисных радикалов приводит к нарушению структуры клеточных мембран и повышению их проницаемости, что усиливает выход в сосудистое русло компонентов цитоплазмы, клеточных органелл и продуктов нарушенного метаболизма клеток, способных непосредственно изменять функциональную активность иммунокомпетентных клеток. В целом иммунометаболические нарушения, возникающие при гипоксии печени, и механизмы 
их развития остаются все еще малоизученными $[8,10,14,19]$.

Отсутствие эффективных средств и способов коррекции нарушений иммунного и метаболического статусов и развивающихся морфологических изменений в ткани печени при ее поражениях определяет целесообразность исследования в эксперименте использования культуральной жидкости аллогенных гепатоцитов (КЖАГ) как отдельно, так и в сочетании с фармакологическими препаратами (антиоксидантами и мембранопротекторами) [5].

Цель исследования - изучить эффективность применения культуральной жидкости аллогенных гепатоцитов и выделенных из нее белков в коррекции метаболических и иммунных нарушений при остром ишемическом поражении печени.

\section{МАТЕРИАЛЫ И МЕТОДЫ ИССЛЕДОВАНИЯ}

Эксперименты проведены на 105 здоровых половозрелых крысах Вистар массой 150-200 г. Все исследования выполнялись в одно и то же время суток с 8 до 12 ч, содержание и выведение животных из эксперимента проводили с соблюдением принципов, изложенных в Конвенции по защите позвоночных животных, используемых для экспериментальных и других целей (г. Страсбург, Франция, 1986), и согласно правилам лабораторной практики РФ (приказ МЗ РФ № 267 от 19.06.2003 г.).

Острое ишемическое поражение печени (ОИПП) вызывали оперативным методом под внутрибрюшинным гексеналовым наркозом путем пережатия гепатодуоденальной связки в течение 20 минут. Верификация развития структурных изменений в ткани печени производилась гистологическими методами.

Гепатоциты выделяли от аллогенных животных через 5-6 дней после рождения. После забора печени производили ее измельчение в среде 199, клетки из ткани печени извлекали выдавливанием с использованием стеклянного гомогенизатора. Жизнеспособность клеток определяли в тесте с красителем - трипановым синим, при этом клеточные суспензии, содержащие менее 90\% жизнеспособных клеток, не использовали. В течение всех манипуляций с клеточной взвесью температура использованной среды 199 составляла 36-37 $\mathrm{C}$ [5].

Культуральную жидкость аллогенных гепатоцитов (КЖАГ) получали культивировированием в среде $1995 \times 10^{7}$ клеток на 3 мл среды в течение 6 ч.

Для получения белков: из 50-100 мл КЖАГ их осаждали равным объемом $10 \%$ трихлоруксусной кислоты, образовавшийся осадок отделяли цен- трифугированием в течение 20 мин при 1500 g, разводили в 0,9\% растворе хлорида натрия и диализовали в двух сменах фосфатно-солевого буфера $\mathrm{pH}$ 7,2-7,4 в течение 18 часов. После определения концентрации белка и доведения его 0,9\% раствором хлорида натрия до 5 мг/мл полученный раствор фильтровали через стерилизационные мембраны 0,2 мкм, расфасовывали в стерильные флаконы по 2 мл и высушивали на установке лиофильной сушки «VIRTIS».

Полученные КЖГА и выделенные из нее белки вводили крысам сразу после моделирования ишемии печени внутрибрюшинно пятикратно (с 24-часовым интервалом) из расчета 5 мг/кг массы тела [5].

Забор крови у экспериментальных животных осуществлялся под наркозом путем внутрисердечной пункции. Эритроциты и плазму получали из гепаринизированной крови путем центрифугирования. Для оценки функционального состояния гепатоцитов в плазме крови определяли тимоловую пробу (ТП), активность аспартат- и аланинаминотрансфераз (АСТ, АЛТ), щелочной фосфатазы (ЩФ), гаммаглутаминтранспептидазы (ГГТ), содержание билирубина (БР), фибриногена (ФГ), протромбиновый индекс (ПТИ).

Интенсивность процессов ПОЛ оценивали по содержанию в плазме крови и эритроцитах ацилгидроперекисей (АГП) и малонового диальдегида (МДА). Для оценки состояния антиоксидантной системы определяли методом прямого/конкурентного твердофазного иммуноферментного анализа (ИФА) активность супероксиддисмутазы (СОД), каталазы и общую антиокислительную активность (ОАА). Уровень стабильных метаболитов оксида азота $\left(\mathrm{CM}_{\mathrm{ON}}\right)$ выявляли с применением набора для твердофазного ИФА.

Развитие гуморального иммунного ответа (ГИО) на эритроциты барана (ЭБ) оценивали на пятые сутки после иммунизации по содержанию в селезенке антителообразующих клеток (АОК). Гиперчувствительность замедленного типа (ГЗТ) индуцировали внутрибрюшинным введением ЭБ (сенсибилизирующая доза). Через 4 суток в подушечку стопы правой лапки вводили разрешающую дозу ЭБ. О выраженности ГЗТ судили по разнице масс (РМ) регионарного и контрлатерального лимфатических узлов и по разнице количества в них кариоцитов (РК) [18].

Выделение нейтрофилов из полученной крови проводили на градиенте плотности фиколл-урографина $(\rho=1,078)$. Фагоцитарная активность нейтрофилов периферической крови оценивалась по фагоцитарному показателю, фагоцитарному числу и индексу активности фагоцитоза (ФП, ФЧ, ИАФ), а кислородзависимую - по 
НСТ-тестам: спонтанному (НСТ-сп.) и стимулированному опсонизированным и неопсонизированным зимозаном (НСТ-ст. о/з, НСТ-ст. н/з), коэффициентам опсонизации, активации на опсонизированный и неопсонизированный зимозан (КО, КАо, КАн) [6].

Для морфологического подтверждения развития моделируемых патологических изменений и комплексной оценки эффективности коррекции нарушений проведено гистологическое исследование печени. Кусочки органа фиксировали в $10 \%$ нейтральном формалине на $0,1 \mathrm{M}$ фосфатном буфере $\mathrm{pH}=7,2$ и заливали в парафин. Парафиновые срезы толщиной 7-10 мкм окрашивали гематоксилином и эозином. Микроскопическое исследование гистологических препаратов проводили с использованием медико-биологического микроскопа Nikon Eclipse Ci$S$ со штатной цифровой камерой производства «Nikon Corporation», Япония при разных увеличениях объектива $(\times 4, \times 10, \times 20, \times 40)$.

С помощью пакета компьютерных программ Microsoft Excel 2010 полученный цифровой материал подвергали статистической обработке с вычислением средних величин (М), ошибки средней арифметической (m). Существенность различий оценивали по U-критерию. Статистически значимыми считали различия с $\mathrm{p}<0,05$.

\section{РЕЗУЛЬТАТЫ ИССЛЕДОВАНИЯ И ИХ ОБСУЖДЕНИЕ}

У животных с ОИПП морфологически по сравнению с контролем (интактными животными) в печени развивались дегенеративные изменения в виде крупнокапельной жировой дистрофии гепатоцитов, захватывающие обширные участки ткани по распространенности близки к диффузному характеру поражения. Границы гепатоцитов нечеткие, балочная структура строения долек нарушена, нередко встречались мелкоочаговые некрозы гепатоцитов с развитием слабо выраженной нейтрофильно-макрофагальной воспалительной инфильтрации (рис. 1,2 ).

Функциональные нарушения при ОИПП характеризовались развитием следующих биохимических синдромов [15]: цитолиза (увеличение активности АСТ и АЛТ), внутри- и внепеченочного холестаза (повышение активности ЩФ, ГГТ и концентрации БР), токсического поражения гепатоцитов (увеличение содержания БР, активности АЛТ, АСТ, ЩФ, ГГТ, коэффициент ГГТ/АСТ меньше 1, коэффициент де Ритиса больше 1), недостаточности синтетических процессов (снижение ПТИ и ФБ) и воспалительного (повышение ТП) (таблица 1).

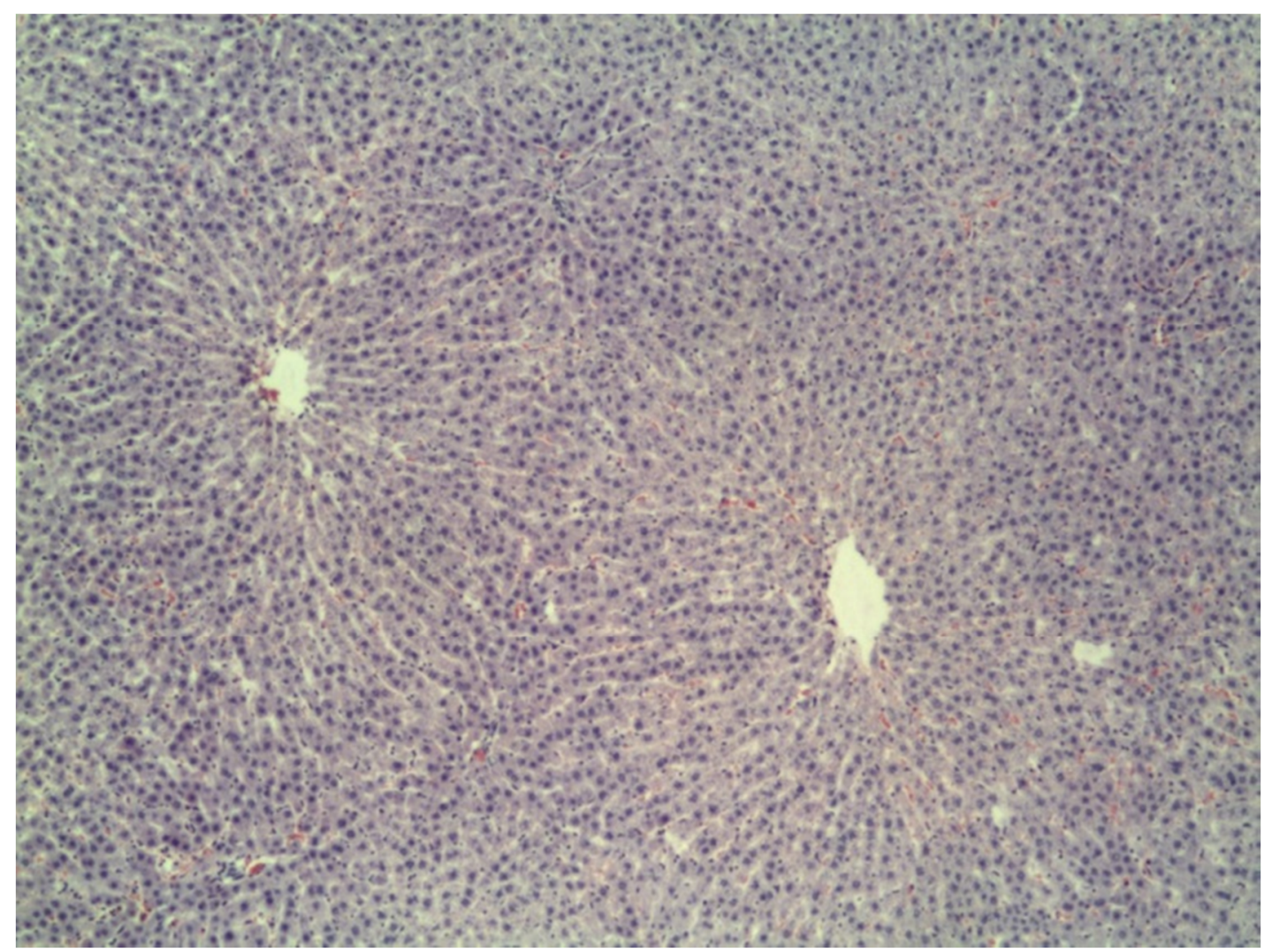

Рис. 1. Гистологическая картина ткани печени у интактного животного. Окраска гематоксилинэозин. Ув. х80.

Fig. 1. Histological picture of liver tissue in an intact animal. Staining with hematoxylin-eosin, $\mathrm{x} 80$. 


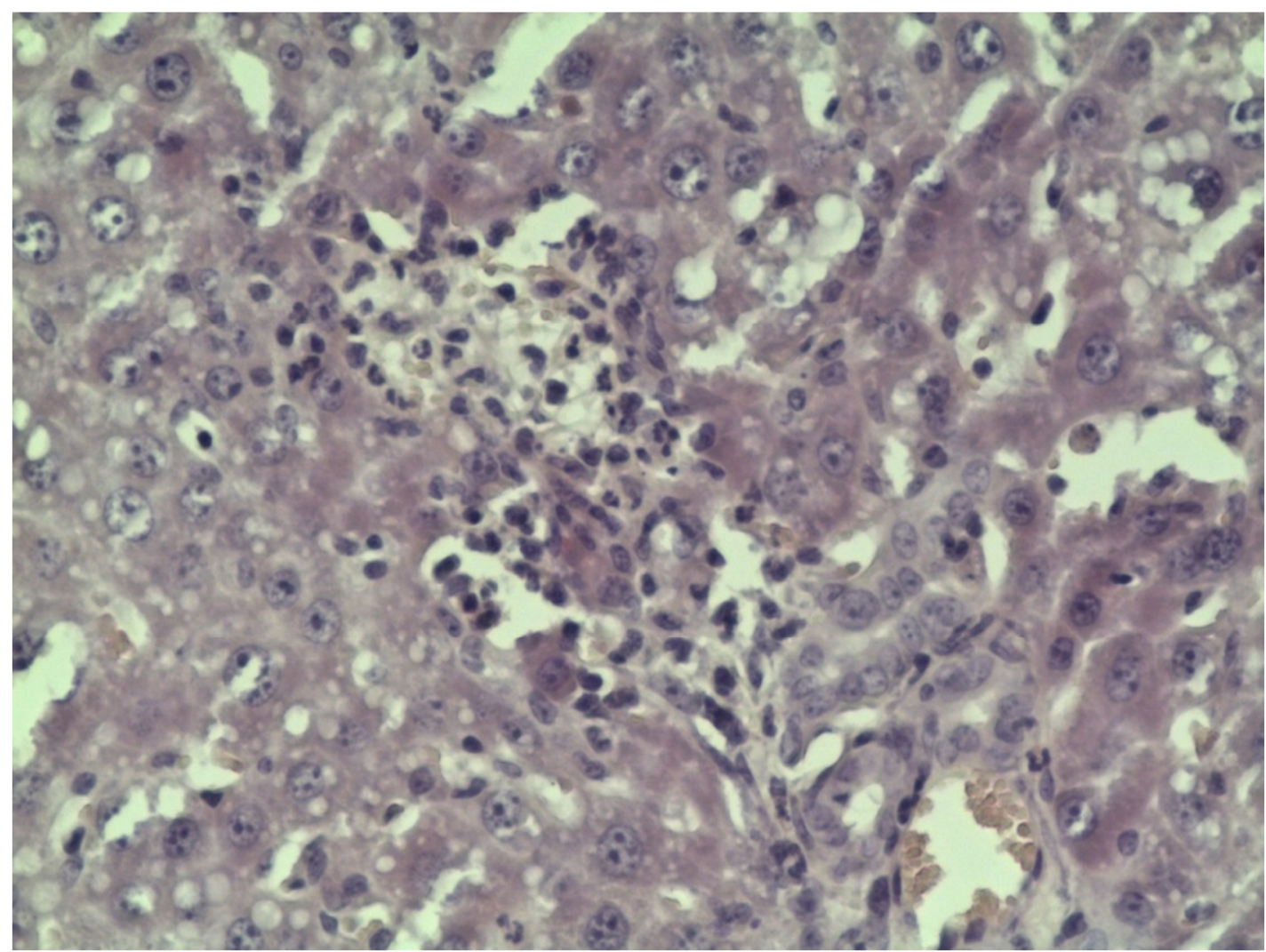

Рис. 2. Дегенеративные изменения ткани печени у животного с ОИПП. Окраска гематоксилин-эозин. Ув. $\mathrm{x} 400$.

Fig. 2. Degenerative changes in liver tissue of an animal with AIDH. Staining with hematoxylin-eosin, $\mathrm{x} 400$.

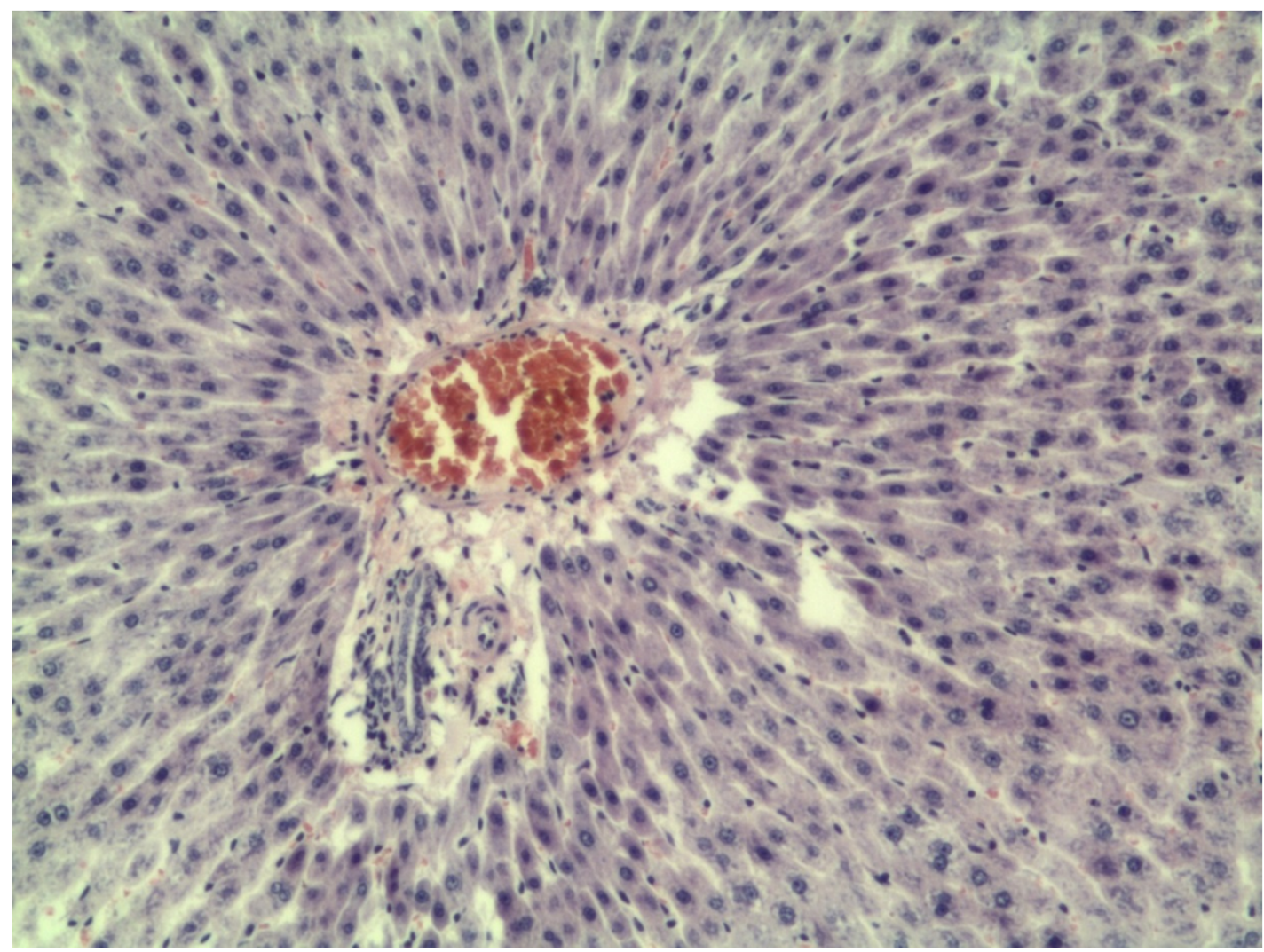

Рис. 3. Гистологическая картина ткани печени у животного с ОИПП, получавшего белки КЖАГ менее 130 кД. Окраска гематоксилин-эозин. Ув. х200.

Fig.3 Histological picture of liver tissue in an animal with AIDH who received CFAH proteins. Staining with hematoxylin-eosin, $\mathrm{x} 200$. 
Белки аллогенных гепатоцитов и их влияние на функциональную активность при остром ишемическом поражении печени $(\mathrm{M} \pm \mathrm{m})$

Allogeneic hepatocyte proteins and their effect on functional activity in acute ischemic liver damage $(\mathrm{M} \pm \mathrm{m})$

\begin{tabular}{|c|c|c|c|c|c|c|c|}
\hline \multirow[b]{3}{*}{$\begin{array}{c}\text { Показатели } \\
\text { Indicators }\end{array}$} & \multirow[b]{3}{*}{$\begin{array}{c}\text { Единицы } \\
\text { измерения } \\
\text { Unit } \\
\text { of measure }\end{array}$} & 1 & 2 & 3 & 4 & 5 & 6 \\
\hline & & \multirow[b]{2}{*}{$\begin{array}{c}\text { Контрольная } \\
\text { группа } \\
\text { Control group }\end{array}$} & \multicolumn{5}{|c|}{$\begin{array}{c}\text { Острая ишемия печени и введение: } \\
\text { Acute liver ischemia and injection of: }\end{array}$} \\
\hline & & & - & $\begin{array}{c}\text { КЖАГ } \\
\text { СFAH }\end{array}$ & $\begin{array}{l}\text { Белки КЖАГ } \\
\text { СFАН proteins }\end{array}$ & $\begin{array}{c}\text { Белки КЖАГ } \\
\text { с ММ менее } \\
130 \text { кДа } \\
\text { CFAH proteins } \\
\text { with MM less } \\
130 \mathrm{kDa} \\
\end{array}$ & $\begin{array}{c}\text { Белки КЖАГ } \\
\text { с ММ более } \\
130 \text { кДа } \\
\text { CFAH proteins } \\
\text { with MM more } \\
130 \mathrm{kDa} \\
\end{array}$ \\
\hline $\begin{array}{l}\text { AЛT } \\
\text { ALT }\end{array}$ & $\begin{array}{l}\mathrm{E} / \pi \\
\mathrm{U} / \mathrm{L}\end{array}$ & $20.3 \pm 2.1$ & $49.5 \pm 4.0^{*} 1$ & $30.7 \pm 2.3^{* 1,2}$ & $29.0 \pm 1.8^{* 1,2}$ & $27.4 \pm 2.5^{* 1,2}$ & $51.2 \pm 5.1^{* 1,3-5}$ \\
\hline $\begin{array}{c}\text { ПТИ } \\
\text { PТІ }\end{array}$ & $\%$ & $61.3 \pm 3.3$ & $37.8 \pm 1.3^{* 1}$ & $58.7 \pm 2.3^{*} 2$ & $60.3 \pm 2.9^{*} 2$ & $62.4 \pm 4.1^{*} 2$ & $40.2 \pm 1.8^{* 1,3-5}$ \\
\hline $\begin{array}{l}\text { ACT } \\
\text { AST }\end{array}$ & $\begin{array}{l}\mathrm{E} / \pi \\
\mathrm{U} / \mathrm{L}\end{array}$ & $27.4 \pm 3.2$ & $56.8 \pm 3.7^{*} 1$ & $41.2 \pm 2^{* 1,2}$ & $39.5 \pm 2.8^{* 1,2}$ & $38.1 \pm 2.4^{* 1,2}$ & $57.4 \pm 4.5^{* 1,3-5}$ \\
\hline $\begin{array}{l}\text { ГГТ } \\
\text { GGT }\end{array}$ & $\begin{array}{l}\mathrm{E} / \pi \\
\mathrm{U} / \mathrm{L}\end{array}$ & $4.7 \pm 0.8$ & $14.0 \pm 0.8^{*} 1$ & $9.3 \pm 1.9^{* 1,2}$ & $8.2 \pm 1.4^{* 1,2}$ & $7.9 \pm 1.7^{* 1,2}$ & $12.9 \pm 1.8^{* 1,3-5}$ \\
\hline $\begin{array}{r}\text { Щ } \\
\text { ALP } \\
\end{array}$ & $\begin{array}{l}\mathrm{E} / л \\
\mathrm{U} / \mathrm{L}\end{array}$ & $235 \pm 10.4$ & $1136.3 \pm 95.6^{* 1}$ & $382.5 \pm 12.3^{* 1,2}$ & $401.3 \pm 15.2^{* 1,2}$ & $391.3 \pm 11.8^{* 1,2}$ & $987.9 \pm 85.6^{* 1,3-5}$ \\
\hline $\begin{array}{r}\text { Коэффиц } \\
\text { Ритиса (А } \\
\text { AST/AL }\end{array}$ & $\begin{array}{l}\text { циент де } \\
\text { JTT / АCТ) } \\
\text { LT ratio }\end{array}$ & $1.32 \pm 0.03$ & $1.15 \pm 0.03^{* 1}$ & $1.34 \pm 0.02^{* 2}$ & $1.36 \pm 0.04^{* 2}$ & $1.4 \pm 0.07^{*} 2$ & $1.12 \pm 0.04^{* 1,3-5}$ \\
\hline $\begin{array}{l}\text { ТП } \\
\text { TТ }\end{array}$ & $\begin{array}{l}\text { Ед. S-H } \\
\text { S-H unit }\end{array}$ & $2.4 \pm 0.1$ & $3.7 \pm 0.08^{* 1,2}$ & $2.7 \pm 0.1^{* 1,2}$ & $2.83 \pm 0.12^{* 1,2}$ & $2.61 \pm 0.11^{* 1,2}$ & $3.9 \pm 0.2^{* 1,3-5}$ \\
\hline $\begin{array}{r}\Gamma \Gamma \mathrm{T} / 1 \\
\mathrm{GGT} /\end{array}$ & $\begin{array}{l}\mathrm{ACT} \\
\text { /AST }\end{array}$ & $0.17 \pm 0.02$ & $0.25 \pm 0.03^{* 1}$ & $0.23 \pm 0.01^{*} 1$ & $0.20 \pm 0.02$ & $0.21 \pm 0.03$ & $0.22 \pm 0.03^{* 1}$ \\
\hline $\begin{array}{l}\Phi \Gamma \\
\mathrm{FG}\end{array}$ & $\begin{array}{l}\Gamma / \pi \\
g / L\end{array}$ & $3.9 \pm 0.04$ & $2.2 \pm 0.02$ & $3.5 \pm 0.08^{* 1,2}$ & $3.8 \pm 0.11^{*} 2$ & $3.9 \pm 0.07^{* 2,4}$ & $2.5 \pm 0.4^{* 1,3-5}$ \\
\hline $\begin{array}{l}\mathrm{BP} \\
\mathrm{BR}\end{array}$ & $\begin{array}{c}\text { мкмоль/л } \\
\mu \mathrm{mol} / \mathrm{L}\end{array}$ & $4.9 \pm 0.9$ & $19.6 \pm 1.3^{*} 1$ & $7.1 \pm 0.4^{* 1,2}$ & $6.9 \pm 0.4^{* 1,2}$ & $6.7 \pm 0.3^{* 1,2}$ & $18.4 \pm 1.7^{* 1,3-5}$ \\
\hline
\end{tabular}

Примечание: на этой и всех следующих таблицах звездочкой $\left(^{*}\right)$ определены достоверные отличия средних арифметических ( $\mathrm{p}=0,05)$; цифры рядом со звездочкой поясняют, по отношению к показателям какой из групп даны эти различия. КЖАГ - культуральная жидкость аллогенных гепатоцитов; МM - молекулярная масса; АЛТ - аланинаминотрансфераза; АСТ - аспартатаминотрансфераза; ГГТ - гамма-глютамилтранспептидаза; ЩФ - щелочная фосфатаза; ПТИ - протромбиновый индекс; БР - билирубин; ТП - тимоловая проба; ФГ - фибриноген.

Note: on this and all the following tables significant differences of arithmetic averages $(\mathrm{p}=0.05)$ were noted in an asterisk $\left({ }^{*}\right)$; numbers next to an asterisk $\left(^{*}\right)$ explain in relation to the indicators of which group these differences are given. CFAH - culture fluid of allogeneic hepatocytes; MM - molecular mass; AST - aspartate aminotransferase; ALT - alanine aminotransferase; ALP - alkaline phosphatase; GGT - gamma-glutamyltranspeptidase; BR - bilirubin; PTI - prothrombin index; FG - fibrinogen; TT - thymol test.

У животных, получавших белки КЖАГ с молекулярной массой (ММ) больше 130 кДа, коррекции и (или) нормализации нарушений биохимических параметров функциональной активности гепатоцитов, вызванных острой ишемией печени, не наблюдалось.

Введение животным с ОИПП КЖАГ нормализовало ПТИ и соотношение АСТ/АЛТ не влияло на коэффициент ГГТ/АСТ, а остальные исследованные параметры функционально- метаболической активности гепатоцитов приближало к значениям контрольной группы, но не до их уровня. Применение цельных (не разделенных на фракции) белков КЖАГ или белков КЖАГ с ММ менее 130 кДа оказалось более эффективным, поскольку, по сравнению с КЖАГ, дополнительно нормализует уровень ФГ и коэффициент ГГТ/АСТ (таблица 1). При морфологическом исследовании печени у животных с ОИПП, получавших белки КЖАГ с ММ менее 
130 кД, в портальных трактах наблюдались неравномерное полнокровие сосудов и явления отека, в перипортальных отделах ткань печени без дегенеративных изменений: гепатоциты с гомогенной цитоплазмой и четкими границами образуют упорядоченно направленные и хорошо контурирующиеся печеночные балки. В области центролобулярных отделов долек балочное строение печеночной ткани нечеткое, в цитоплазме гепатоцитов наблюдались явления гиалиново-капельной дистрофии, некроз отдельных клеток (рис. 3).

Установлено, что у животных с ОИПП на системном (плазма крови) и локальном (эритроциты) уровне наблюдается активация ПОЛ (увеличение содержания МДА и АГП), развитие оксидантного стресса (снижение ОАА, активности СОД и каталазы), снижение в плазме крови концентрации стабильных метаболитов оксида азота (таблица 3).

Таблица 2

Table 2

Белки аллогенных гепатоцитов и их влияние на метаболические параметры эритроцитов и плазмы крови при остром ишемическом поражении печени $(\mathrm{M} \pm \mathrm{m})$

The effect of allogeneic hepatocyte proteins on metabolic parameters of blood plasma and erythrocytes in acute ischemic liver damage $(\mathrm{M} \pm \mathrm{m})$

\begin{tabular}{|c|c|c|c|c|c|c|c|c|}
\hline \multirow{5}{*}{$\begin{array}{c}\text { Показатели } \\
\text { Indicators }\end{array}$} & \multirow{5}{*}{$\begin{array}{c}\text { Единицы } \\
\text { измерения } \\
\text { Unit } \\
\text { of measure }\end{array}$} & 1 & 2 & 3 & 4 & & 5 & 6 \\
\hline & & \multirow{4}{*}{$\begin{array}{c}\text { Контрольная } \\
\text { группа } \\
\text { Control group }\end{array}$} & \multicolumn{6}{|c|}{$\begin{array}{l}\text { Острая ишемия печени и введение: } \\
\text { Acute liver ischemia and injection of: }\end{array}$} \\
\hline & & & \multirow{3}{*}{-} & \multirow{3}{*}{$\begin{array}{r}\text { КЖАГ } \\
\text { СFАН }\end{array}$} & \multirow{3}{*}{\begin{tabular}{|c|} 
Белки \\
КЖАГ \\
CFAH proteins
\end{tabular}} & \multirow{2}{*}{\multicolumn{2}{|c|}{$\begin{array}{c}\text { Белки КЖАГ } \\
\text { с ММ менее } \\
130 \text { кДа }\end{array}$}} & \multirow{2}{*}{$\begin{array}{c}\text { Белки КЖАГ } \\
\text { с ММ более } \\
130 \text { кДа }\end{array}$} \\
\hline & & & & & & & & \\
\hline & & & & & & $\begin{array}{r}\text { CFA } \\
\text { MN }\end{array}$ & $\begin{array}{l}\text { H proteins with } \\
\mathrm{M} \text { less } 130 \mathrm{kDa}\end{array}$ & $\begin{array}{l}\text { CFAH proteins with } \\
\text { MM more } 130 \mathrm{kDa}\end{array}$ \\
\hline \multicolumn{9}{|c|}{ Плазма крови } \\
\hline \multicolumn{9}{|c|}{ Blood plasma } \\
\hline $\begin{array}{l}\text { OAA } \\
\text { TAA }\end{array}$ & $\%$ & $42.8 \pm 2.1$ & $32.7 \pm 2.3^{* 1}$ & $44.7 \pm 3.1^{* 2}$ & $47.1 \pm 5.2^{*} 2$ & & $44 . \pm 4.1^{* 2}$ & $34.7 \pm 1.9^{* 1,3,4,5}$ \\
\hline $\begin{array}{l}\text { СОД } \\
\text { SOD }\end{array}$ & $\begin{array}{l}\text { усл. ед./мл } \\
\text { U.U./ml }\end{array}$ & $12.0 \pm 0.7$ & $6.1 \pm 1^{*} 1$ & $13.9 \pm 1.1^{* 2}$ & $14.5 \pm 1.2^{*} 2$ & & $15.1 \pm 2.2^{*} 2$ & $5.9 \pm 0.8^{* 1,3,4,5}$ \\
\hline $\begin{array}{l}\text { МДА } \\
\text { MDA }\end{array}$ & $\begin{array}{c}\text { МКМоль/л } \\
\mu \mathrm{mol} / \mathrm{L}\end{array}$ & $2.6 \pm 1$ & $8.3 \pm 0.9^{* 1}$ & $2.3 \pm 0.11^{*} 2$ & $2.4 \pm 0.1^{*} 2$ & & $.46 \pm 0.08^{* 2}$ & $7.8 \pm 0.7^{* 1,3,4,5}$ \\
\hline $\begin{array}{l}\mathrm{A} \Pi \Pi \\
\text { АНР }\end{array}$ & $\begin{array}{l}\text { усл. ед. } \\
\text { C.U. }\end{array}$ & $0.82 \pm 0.08$ & $2.6 \pm 0.1^{* 1}$ & $0.81 \pm 0.02^{* 2}$ & $0.79 \pm 0.03^{* 2}$ & & $0.8 \pm 0.02^{*} 2$ & $2.4 \pm 0.14^{* 1,3,4,5}$ \\
\hline $\begin{array}{c}\mathrm{CM}_{\mathrm{ON}} \\
\mathrm{SM}_{\mathrm{ON}}\end{array}$ & $\begin{array}{c}\text { МКмоль/л } \\
\mu \mathrm{mol} / \mathrm{L}\end{array}$ & $7.1 \pm 0.3$ & $3.8 \pm 0.07^{* 1}$ & $6.2 \pm 0.2^{* 1,2}$ & $6.0 \pm 0.1^{* 1,2}$ & & $6.4 \pm 0.22^{* 1,2}$ & $4.1 \pm 0.32^{* 1,3,4,5}$ \\
\hline $\begin{array}{c}\text { Каталаза } \\
\text { Kat }\end{array}$ & $\begin{array}{l}\text { мкат/Л } \\
\text { mkat/L }\end{array}$ & $13.4 \pm 1$ & $8.2 \pm 1^{*} 1$ & $13.7 \pm 1.5^{*}$ & $14.8 \pm 2.7^{*} 2$ & & $15.6 \pm 2.9^{*} 2$ & $8.6 \pm 0.7^{* 1,3,4,5}$ \\
\hline \multicolumn{9}{|c|}{ Эритроциты } \\
\hline \multicolumn{9}{|c|}{ Red blood cells } \\
\hline $\begin{array}{l}\text { OAA } \\
\text { TAA }\end{array}$ & $\%$ & $45.6 \pm 3.0$ & $37.5 \pm 2.8^{* 1}$ & $46.1 \pm 3.5^{*} 2$ & $49.1 \pm 4$ & & $50.5 \pm 5.1^{* 2}$ & $38.1 \pm 1.4^{* 1,3,4,5}$ \\
\hline $\begin{array}{l}\text { СОД } \\
\text { sOD }\end{array}$ & $\begin{array}{c}\text { усл. ед./мЛ } \\
\text { С.U./ml }\end{array}$ & $22.1 \pm 1.3$ & $10.4 \pm 0.8^{* 1}$ & $21.3 \pm 1.7^{*} 2$ & $24.6 \pm 2$. & & $23.8 \pm 1.7^{* 2}$ & $12.5 \pm 2.2^{*} 1,3,4,5$ \\
\hline $\begin{array}{l}\mathrm{A} \Gamma \Pi \\
\mathrm{AHP}\end{array}$ & $\begin{array}{l}\text { усл. ед. } \\
\text { с.U. }\end{array}$ & $0.11 \pm 0.02$ & $1.04 \pm 0.04^{* 1}$ & $0.35 \pm 0.04^{* 1,2}$ & $0.4 \pm 0.02$ & & $0.38 \pm 0.03^{* 1,2}$ & $0.98 \pm 0.05^{* 1,3,4,5}$ \\
\hline $\begin{array}{l}\text { МДА } \\
\text { МDА }\end{array}$ & $\begin{array}{c}\text { Мкмоль/л } \\
\mu \mathrm{mol} / \mathrm{L}\end{array}$ & $0.28 \pm 0.03$ & $3.8 \pm 0.12^{* 1}$ & $0.54 \pm 0.12^{* 1,2}$ & $0.6 \pm 0.05$ & $5^{* 1,2}$ & $0.71 \pm 0.04^{*} 1,2$ & $3.5 \pm 0.2^{* 1,3,4,5}$ \\
\hline $\begin{array}{l}\mathrm{CE} \Gamma \\
\mathrm{SCE} \\
\end{array}$ & $\begin{array}{l}10^{14} \mathrm{\Gamma} / \ni \mathrm{p} \\
10^{12} \mathrm{~g} / \mathrm{RBC} \\
\end{array}$ & $3.1 \pm 0.1$ & $1.4 \pm 0.03^{* 1}$ & $3.04 \pm 0.1^{*} 2$ & $2.94 \pm 0.0$ & $8^{*} 2$ & $3.2 \pm 0.2^{*} 2$ & $1.5 \pm 0.1^{*} 1,3,4,5$ \\
\hline $\begin{array}{l}\text { CEЭ } \\
\text { ESC }\end{array}$ & $\%$ & $51.7 \pm 1.8$ & $24.2 \pm 1.1^{* 1}$ & $53.7 \pm 4.1^{*} 2$ & $48.4 \pm 3$ & & $47.5 \pm 4.8^{* 2}$ & $26.7 \pm 2.5^{* 1,3,45}$ \\
\hline $\begin{array}{l}\text { Каталаза } \\
\text { Kat }\end{array}$ & $\begin{array}{c}\text { мкат/л } \\
\text { mkat/L }\end{array}$ & $12.4 \pm 1.1$ & $8.1 \pm 0.3^{*} 1$ & $17.7 \pm 1.9^{* 1,2}$ & $18.4 \pm 1.3$ & $3^{* 1,2}$ & $19.7 \pm 2.5^{* 1,2}$ & $7.8 \pm 0.9^{* 1,3,4,5}$ \\
\hline
\end{tabular}

Примечание: МДА - малоновый диальдегид; АГП - ацилгидроперекиси; ОАА - общая антиокислительная активность; СОД - супероксиддисмутаза; СМ СЭЭ - сорбционная емкость эритроцитов; СЕГ - сорбционная емкость гликокаликса.

Note: MDA - malondialdehyde; AHP - acylhydroperoxides; TAA - total antioxidant activity; SOD - superoxide dismutase; $\mathrm{SM}_{\mathrm{ON}}$ - stable metabolites of nitric oxide; ESC - erythrocyte sorption capacity; SCE - sorption capacity glycocalyx. 
Влияние белков аллогенных гепатоцитов на формирование адаптивного иммунного ответа и метаболическую и функциональную активность нейтрофилов периферической крови при остром ишемическом поражении печени $(\mathrm{M} \pm \mathrm{m})$

The effect of allogeneic hepatocyte proteins on the formation of an adaptive immune response and the functional and metabolic activity of peripheral blood neutrophils in acute ischemic liver damage $(\mathrm{M} \pm \mathrm{m})$

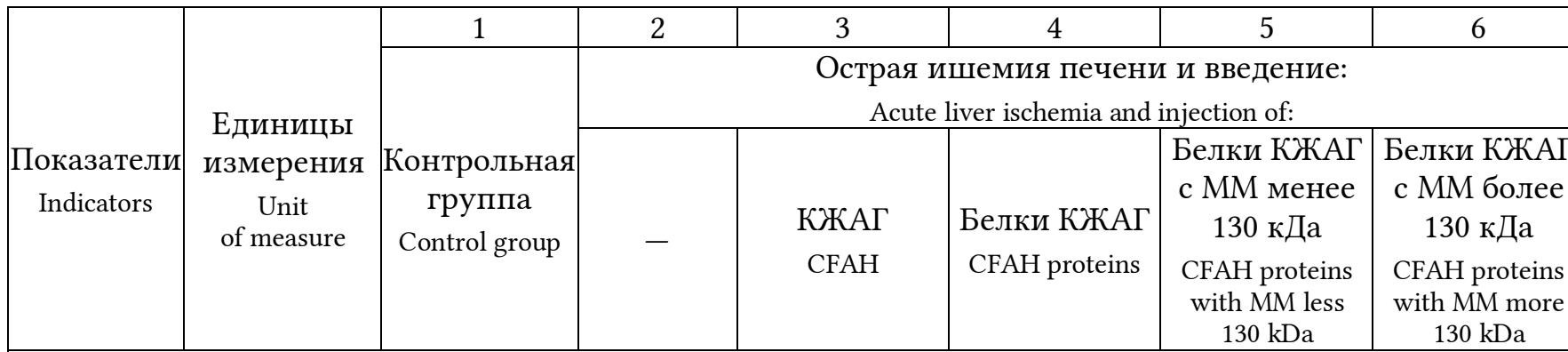

ГИО и ГЗТ

Humoral immune response and delayed type hypersensitivity

\begin{tabular}{|c|c|c|c|c|c|c|c|}
\hline $\begin{array}{l}\mathrm{PM} \\
\mathrm{MD}\end{array}$ & $\begin{array}{l}\mathrm{M \Gamma} \\
\mathrm{mg}\end{array}$ & $3.1 \pm 0.07$ & $2.0 \pm 0.04^{* 1}$ & $3.15+0.05^{* 2}$ & $3.2 \pm 0.08^{* 2}$ & $3.14 \pm 0.05^{* 2}$ & $2.1 \pm 0.07^{* 1,3,4,5}$ \\
\hline $\begin{array}{l}\mathrm{PK} \\
\mathrm{KD}\end{array}$ & $\begin{array}{c}10^{6} \\
\text { кариоцитов } \\
10^{6} \text { kariocytes }\end{array}$ & $1.8 \pm 0.08$ & $0.9 \pm 0.02^{* 1}$ & $1.93 \pm 0.1^{*} 2$ & $1.84 \pm 0.07^{* 2}$ & $1.77 \pm 0.06^{* 2}$ & $0.82 \pm 0.05^{*} 1,3,4,5$ \\
\hline $\begin{array}{l}\mathrm{AOK} \\
\mathrm{APC}\end{array}$ & $\begin{array}{c}\text { тыс/орган } \\
\text { t./organ }\end{array}$ & $19.7 \pm 1.4$ & $8.4 \pm 0.9^{*} 1$ & $14.2 \pm 1.2^{* 1,2}$ & $15.1 \pm 1.8^{*} 1.2$ & $13.7 \pm 2.1^{*} 1.2$ & $7.8 \pm 0.5^{* 1,3,4,5}$ \\
\hline
\end{tabular}

Метаболическая и функциональная активность нейтрофилов периферической крови

Metabolic and functional activity of peripheral blood neutrophils

\begin{tabular}{|c|c|c|c|c|c|c|c|}
\hline $\begin{array}{c}\text { ИАФ } \\
\text { PAI }\end{array}$ & - & $1.54 \pm 0.1$ & $0.7 \pm 0.04^{* 1}$ & $1.66 \pm 0.08^{*} 2$ & $1.73 \pm 0.12^{*} 2$ & $1.8 \pm 0.2^{*} 2$ & $0.75 \pm 0.03^{* 1,3,4,5}$ \\
\hline $\begin{array}{c}\Phi \Pi \\
\text { PI }\end{array}$ & $\begin{array}{l}\text { абс. } \\
\text { abs. }\end{array}$ & $61.7 \pm 3.6$ & $46.8 \pm 2.1^{*} 1$ & $65.0 \pm 2.6^{*} 2$ & $66.3 \pm 4.8^{*} 2$ & $63.7 \pm 3.5^{*} 2$ & $44.3 \pm 2.5^{* 1,3,4,5}$ \\
\hline $\begin{array}{l}\Phi \Psi \\
\mathrm{PN}\end{array}$ & $\begin{array}{l}\text { абс. } \\
\text { abs. }\end{array}$ & $2.5 \pm 0.06$ & $1.5 \pm 0.05^{*} 1$ & $2.55 \pm 0.3^{* 2}$ & $2.61 \pm 0.3^{*} 2$ & $2.8 \pm 0.3^{*} 2$ & $1.7 \pm 0.16^{* 1,3,4,5}$ \\
\hline $\begin{array}{l}\mathrm{KO} \\
\mathrm{OC}\end{array}$ & - & $1.4 \pm 0.08$ & $1.02 \pm 0.03^{*} 1$ & $1.39 \pm 0.08^{*} 2$ & $1.16 \pm 0.04^{* 1,3}$ & $1.4 \pm 0.03^{*} 2,4$ & $1.07 \pm 0.02^{* 1,3,4,5}$ \\
\hline $\begin{array}{l}\text { HCT-сп. } \\
\text { NBT-sp. }\end{array}$ & $\mathrm{mOD}$ & $0.80 \pm 0.02$ & $0.50 \pm 0.02^{* 1}$ & $0.76 \pm 0.1^{*} 2$ & $0.74 \pm 0.05^{*}$ & $0.8 \pm 0.05^{*} 2$ & $0.52 \pm 0.03^{*} 1,3,4,5$ \\
\hline \begin{tabular}{|c|} 
НСТ-ст. н/3 \\
NBT-ind $n / z$
\end{tabular} & $\mathrm{mOD}$ & $0.9 \pm 0.02$ & $0.54 \pm 0.04^{* 1}$ & $1.01 \pm 0.03^{*} 2$ & $1.1 \pm 0.2^{*} 2$ & $0.94 \pm 0.07^{*} 2$ & $0.57 \pm 0.02^{* 1,3,4,5}$ \\
\hline \begin{tabular}{|c|} 
НCT-ст. o/3 \\
NBT-ind o/z
\end{tabular} & $\mathrm{mOD}$ & $1.3 \pm 0.04$ & $0.55 \pm 0.05^{* 1}$ & $1.4 \pm 0.07^{* 2}$ & $1.28 \pm 0.1^{*} 2$ & $1.33 \pm 0.09^{*} 2$ & $0.61 \pm 0.03^{* 1,3,4,5}$ \\
\hline $\begin{array}{l}\text { KAo } \\
\mathrm{ACo} / \mathrm{z}\end{array}$ & - & $1.65 \pm 0.03$ & $1.12 \pm 0.02^{*} 1$ & $1.84 \pm 0.09^{* 1,2}$ & $1.73 \pm 0.03^{*}$ & $1.7 \pm 0.05^{*} 2$ & $1.17 \pm 0.04^{* 1,3,4,5}$ \\
\hline $\begin{array}{l}\mathrm{KAH} \\
\mathrm{ACn} / \mathrm{z}\end{array}$ & - & $1.14 \pm 0.08$ & $1.1 \pm 0.03$ & $1.33 \pm 0.04^{* 1,2}$ & $1.5 \pm 0.14^{* 1,2}$ & $1,18 \pm 0,06^{* 3,4}$ & $1.1 \pm 0.02^{* * 1,3,4,5}$ \\
\hline
\end{tabular}

Примечание: АОК - количество антителообразующих клеток; РМ - разница масс контралатерального и регионарного подколенных лимфатических узлов; РК - разница количества в них кариоцитов; Ф - фагоцитарный показатель; ФЧ - фагоцитарное число; ИАФ - индекс активности фагоцитоза; НСТ-тест - реакция восстановления нитросинего тетразолия: спонтанная (НСТ-сп.) и стимулированная опсонизированным и неопсонизированным зимозаном (НСТ-ст. о/з, НСТ-ст. н/з); КО, КАн, КАо - коэффициенты опсонизации, активации на опсонизированный и неопсонизированный зимозан.

Note: AFC - is the number of antibody-producing cells; MD - the difference in mass of regional and contralateral popliteal lymph nodes; KD - the difference in the number of karyocytes in them; PI - is a phagocytic index; PN - phagocytic number; PAI - phagocytosis activity index; NBT-test - is the reduction reaction of nitroblue tetrazolium: spontaneous (NBT-sp.) and stimulated by opsonized and nonopsonized zymosan (NBT-ind. o/z, NBT-ind. n/z); OC, ACo/z, ACn/z - coefficients of opsonization, activation for opsonized and nonopsonized zymosan. 
Введение белков КЖАГ с ММ более 130 кДа не влияло на активацию ПОЛ, развитие оксидантного стресса на общем (плазма крови) и локальном (эритроциты) уровне, обусловленные острой ишемией печени. Введение КЖАГ, неразделенных белков КЖАГ или белков КЖАГ с ММ менее 130 кДа нормализует параметры антиоксидантной защиты на системном и локальном уровне (исключением стала активность каталазы в эритроцитах - коррекция) и приближает к контролю, но не до их значений, содержание $\mathrm{CM}_{\mathrm{ON}}$ в плазме и маркеры ПОЛ в эритроцитах (таблица 2).

Острая ишемия печени приводит к супрессии развития гуморального и клеточного иммунного ответа на ЭБ и снижению фагоцитарной и кислород-зависимой метаболической активности циркулирующих нейтрофилов (за исключением КАн - без изменения) (таблица 3).

Введение белков КЖАГ с ММ больше 130 кДа не влияло на изменения параметров адаптивного и врожденного иммунитета, вызванные острой ишемией ткани печени. Использование КЖАГ, неразделенных белков КЖАГ или белков КЖАГ с ММ менее 130 кДа корригирует формирование ГИО (АОК), нормализует показатели ГЗТ (РМ и РК), фагоцитарной (ФП, ФЧ и ИАФ) и кислород-зависимой метаболической (НСТ-сп., НСТ-ст. н/з и о/з) активности полиморфноядерных лейкоцитов периферической крови. В отличие от КЖАГ, введение которой повышает показатели функционального резерва нейтрофилов (КАн и КАо) с достоверным превышением контрольных значений, белки КЖАГ (без разделения и с ММ менее 130 кД) корригируют или нормализуют эти параметры полиморфноядерных лейкоцитов. Введение белков КЖАГ не разделенных на фракции снижает дополнительные функциональные возможности нейтрофилов (КО) в отношении метаболической активности, а КЖАГ и белки с ММ менее 130 кДа их нормализуют (таблица 3 ).

Таким образом, в условиях ОИПП при анализе корригирующей активности КЖАГ и белков КЖАГ на динамику биохимических маркеров острой ишемии печени, формирование гуморального и клеточного иммунитета, нарушения функциональной и метаболической активности нейтрофилов периферической крови, внутриэритроцитарного метаболизма, активацию свободно-радикального окисления, по степени возрастания эффективности установлена следующая последовательность: КЖАГ; неразделенные белки КЖАГ; белки КЖАГ с ММ менее 130 кДа. Применение белков КЖАГ с ММ более 130 кДа не оказывало корригирующего эффекта.

В литературе имеется большое количество экспериментальных и клинических работ, по- священных коррекции нарушений функции печени, есть исследования по оксидантным, иммунным и эритроцитарным нарушениям и их коррекции при патологии печени $[1,24,26]$.

Однако проблема фармакологической терапии заболеваний печени далека от разрешения, а неудовлетворительные результаты лечения острых и хронических поражений печени, приводящих к развитию печеночной недостаточности, во многом связывают с отсутствием эффективной патогенетической терапии, в связи с чем перспективным направлением в лечении таких состояний является применение клеточных технологий $[7,24,25]$, и в том числе - использование изолированных ксено- и аллогенных гепатоцитов. В настоящее время механизм действия гепатоцитов, применяемых для коррекции нарушений при гепатопатиях нельзя считать окончательно выясненным. Трудно представить, что лечебный эффект связан с органозамещающей функцией трансплантируемых клеток и, вероятно, он обусловлен гуморальными и молекулярными механизмами, отвечающими за активацию функциональной активности гепатоцитов реципиента и регенерацию, путем выработки регуляторных пептидов, среди которых ведущая роль принадлежит факторам роста [15, $21,25]$.

Полученные нами результаты подтверждают вышеизложенное и мы считаем, что перспективным продолжением работы является очистка белков культуральной жидкости аллогенных гепатоцитов с выделением концентрированной активной субстанции белковой природы с дальнейшим созданием на этой основе препарата и его доклиническое испытание на экспериментальных моделях патологии печени.

\section{КОНФЛИКТ ИНТЕРЕСОВ}

Авторы декларируют отсутствие явных и потенциальных конфликтов интересов, связанных с публикацией настоящей статьи.

\section{ИСТОЧНИКИ ФИНАНСИРОВАНИЯ}

Авторы заявляют об отсутствии финансирования.

\section{СООТВЕТСТВИЕ ПРИНЦИПАМ ЭТИКИ}

Исследование одобрено Региональным этическим комитетом. Протокол заседания РЭК № 9 от 9 ноября 2015 года.

\section{ЛИTЕРАTУPA/REFERENCES}

1. Антоненко О.М. Токсические поражения печени: пути фармакологической коррекции. Медицинский совет. 2013; 6: 45-51 [Antonenko O.M. Toxic liver damage: ways of pharmacological correction Meditsinskiy sovet. 2013; 6: 45-51 (in Russ.)] 
2. Галстян Г.М., Макарова П.М., Паровичникова Е.Н. Применение мультипотентных мезенхимальных стволовых клеток для лечения сепсиса. Анестезиология и реаниматология. 2015; 60(5): 59-65 [Galstyan Gennadiy M., Makarova P.M., Parovichnikova E.N. Use of mesenchymal stromal stem cells for the treatment of sepsis. Anesteziologiya $i$ reanimatologiya. 2015; 60(5): 59-65 (in Russ.)]

3. Гараев Г.Ш., Гафарова Ж.Р., Джафарова Р.Э. Изменения состава белков в крови в период синдрома ишемии-реперфузии, моделированного нарушением кровотока в печени. Вестник российской военно-медицинской академии. 2018; 2 (62): 110-114 [Garayev G.Sh., Gafarova J.R., Jafarova R.E. Changes in the composition of proteins in the blood during the period of ischemia-reperfusion syndrome, modeled by a violation of blood flow in the liver. Vestnik rossiyskoy voyenno-meditsinskoy akademii. 2018; 2(62): 110-114 (in Russ.)]

4. Есеева М.Н., Шептулина А.Ф., Рубцов Ю.П. Перспективы создания аутологичных гепатоцитов для лечения печеночной недостаточности. Российский журнал гастроэнтерологии, гепатологии, колопроктологии. 2015; 25(6): 49-57 [Evseyeva M.N., Sheptulina A.F., Rubtsov Yu.P. Prospects of autologous hepatocytes for liver failure treatment. The Russian fournal of Gastroenterology, Hepatology, Coloproctology. 2015; 25(6): 49-57 (in Russ.)]

5. Зинкин В.Ю., Годков М.А. Способ количественной оценки кислородзависимого метаболизма нейтрофильных гранулоцитов человека. Клиническая лабораторная диагностика. 2004; (8): 26-29 [Zinkin V. Yu., Godkov M.A. A method of quantitative evaluation of oxygen-dependent metabolism of human neutrophil granulocytes. Klinicheskaya laboratornaya diagnostika. 2004; (8): 26-29 (in Russ.)]

6. Конопля А.И., Литвинова Е.С., Быстрова Н.А., Разумова М.С., Чуева Т.В. Иммунометаболические нарушения при экспериментальном остром токсическом поражении печени: коррекция ксеногенными и аллогенными гепатоцитами. Becmник трансплантологии и искусственных органов. 2016; 18(2): 91-98 [Konoplya A.I., Litvinova E.S., Bystrova N.A., Razumova M.S., Chuyeva T.V. Immune and metabolic disturbances in experimental acute toxic hepatitis: correction by xenogenic and allogenic hepatocytes. Russian journal of transplantology and artificial organs. 2016; 18(2): 91-98 (in Russ.)]

7. Лепехова С.А., Апарцин К.А., Искра А.И. Роль фактора роста гепатоцитов в регенерации печени. Фундаментальные исследования. 2014;7-1: 187192 [Lepekhova S.A., Apartsin K.A., Iskra A.I. Role of hepatocyte growth factor in liver regeneration. Fundamental'nyye issledovaniya. 2014; 7-1: 187-192 (in Russ.)]

8. Лямина Н.П., Карпова Э.С., Котельникова Е.В. Адаптация к гипоксии и ишемическое прекондиционирование: от фундаментальных исследований к клинической практике. Клиническая медицина. 2014; 92(2): 23-29 [Lyamina N.P., Karpova E.S., Kotelnikova E.V. Adaptation to hypoxia and ischemic preconditioning: from basic research to clinical. Klinicheskaya meditsina. 2014; 92(2): 23-29 (in Russ.)]

9. Медведева С.Ю., Мухлынина Е.А., Булавинцева Т.С., Данилова И.Г. Участие фактора стволовой клетки в репаративной регенерации печени при ее токсическом повреждении. Медицинская иммунология. 2015; 17(S): 32 [Medvedeva S.Yu., Mukhlynina E.A., Bulavintseva T.S., Danilova I.G. Part of the factor of stem cells in reparative regeneration of the liver in its toxicity. Meditsinskaya immunologiya. 2015; 17(S): 32 (in Russ.)]

10. Николаев С.Б., Быстрова Н.А., Лазаренко В.А., Конопля А.И. Иммунометаболические нарушения в условиях гипоксии и их фармакологическая коррекция. Курск: Издательство ГОУ ВПО КГМУ Росздрава России, 2010. 226 с. [Nikolayev S.B., Вystrova N.A., Lazarenko V.A., Konoplya A.I. Immunometabolic disorders in hypoxia and their pharmacological correction. Kursk: Izdatel'stvo GOU VPO KGMU Roszdrava Rossii, 2010. 226 p. (in Russ.)]

11. Онищенко Н.А., Люндуп А.В., Газизов И.М., Деев Р.В., Шагидулин М.Ю., Крашенинников М.Е., Аврамов П.В. Двухфазная динамика воздействия мезенхимальных мультпатентных стромальных клеток (ММСК) костного мозга на печень при моделировании фиброзирующего гепатита. Вестник трансплантологии и искусственных органов. 2011; 13(3): 51-58 [Onishchenko N.A., Lyundup A.V., Gazizov I.M., Deev R.V., Shagidulin M.Y., Krasheninnikov M.E., Avramov P.V. Two-phase dynamics of bone marrow multipotent mesenchymal stromal cells (MMSC) action on liver at modeling of fibrotic hepatitis. Russian journal of transplantology and artificial organs. 2011; 13(3): 51-58 (in Russ.)]

12. Разумова М.С., Литвинова Е.С., Быстрова Н.А., Локтионов А.Л. Функционально-метаболическая активность нейтрофилов периферической крови при использовании ксено-, аллогенных гепатоцитов, фибробластов и их культуральной жидкости при экспериментальном остром токсическом поражении печени. Системный анализ и управление в биомедицнских системах. 2015; 14(4): 714720 [Razumova M.S., Litvinova E.S., Bystrova N.A., Loktionov A.L. Functional and metabolic activity of neutrophils of the peripheric blood when using kseno-, allogenic hepatocytes, fibroblasts and their cultural liquids at the experimental acute toxic hepatitis. Sistemnyy analiz $i$ upravleniye $v$ biomeditsinskikh sistemakh. 2015; 14(4): 714-720 (in Russ.)]

13. Салиенко А.А., Хубутия М.Ш., Чжао А.В., Джаграев К.Р., Андрейцева О.И., Журавель С.В., Сюткин В.Е. Трансплантация печени как радикальный метод лечения конечных стадий заболеваний печени. Практическая медицина. 2010; 8(47): 13-19 [Khubutia M.Sh., Zhao A.V., Dzhagraev K.R., Andreytseva O.I., Zhuravel S.V., Salienko A.A., Syutkin B.E. Liver transplantation as a radical treatment for end-stage liver disease. Prakticheskaya meditsina. 2010; 8(47): 13-19 (in Russ.)]

14. Сухоруков В.П., Булдаков А.В, Машковцев О.В. Сравнительное изучение морфологических изменений ткани печени под воздействием острой ишемии и введении в ишемизированную печень 
различных лекарственных средств. Новые технологии, методы диагностики, лечения, профилактики. Вестник Санкт-Петербургской государственной медицинской академии им. И.И. Мечникова. 2009; 1(30): 78-81 [Sukhorukov V.P., Buldakov A.V, Mashkovtsev O.V. Comparative study of morphological changes in liver tissue under the influence of an acute ischemia and introduction of various medical agents into the ischemic liver. Vestnik Sankt-Peterburgskoy gosudarstvennoy meditsinskoy akademii im. I.I. Mechnikova. 2009; 1(30): 78-81 (in Russ.)]

15. Титов В.Т. Болезни печени. В кн.: Клиническая биохимия. Ткачук В.А., под ред. Москва: ГОЭТАРМедиа. 2006. С. 361-371. [Titov V.T. Liver disease. In: Clinical biochemistry. Tkachuk V.A., editor. Moscow: GOETAR-Media, 2006. P. 361-371 (in Russ.)]

16. Умбаев Б.А., Аскарова Ш.Н., Шалахметова Т.М., Цой А.К., Буланин Д.С. Внутрибрюшинная трансплантация аллогенных гепатоцитов крысам с индуцированным токсическим циррозом печени. Вестник КазНУ. Серия экологическая. 2014.; 1(2-40): 261-270 [Umbayev B.A., Askarova Sh.N., Shalakhmetova T.M., Tsoy A.K., Bulanin D.S. Intraperitoneal transplantation of hepatocytes allogenic rats with induced toxic liver cirrhosis. Vestnik KazNU. Seriya ekologicheskaya. 2014.; 1(2-40): 261-270 (in Russ.)]

17. Уразметова М.Д., Хаджибаев Ф.А., Мирзакулов А.Г. Анализ показателей иммуногенеза при алло- и ксенотрансплантации эмбриональных гепатоцитов. Вестник экстренной медицины. 2018; 11(2): 57-63 [Urazmetova M.D., Khadzhibaev F.A., Mirzakulov A.G. The analysis of the indices of immunogenesis in ALLO - and xenotransplantation of embryonic hepatocytes. Vestnik ekstrennoy meditsiny. 2018; 11(2): 57-63 (in Russ.)]

18. Федовеева В.Н., Порядин Г.В., Ковальчук Л.В., Чередеев А.Н., Коган В.Ю. Руководство по иммунологическим и аллергологическим методам в гигиенических исследованиях. Москва: Промедэк, 1993. 319 c. [Fedoveyeva V.N., Poryadin G.V., Koval'chuk L.V., Cheredeyev A.N.; Kogan V.Yu. Guidance on immunological and allergic methods in hygienic studies. Moscow: Promedek, 1993. 319 p. (in Russ.)]

19. Ходосовский М.Н. Коррекция окислительных повреждений при синдроме ишемииреперфузии печени. Журнал Гродненского государственного медицинского университета. 2016; 4(56): 20-25 [Khodosovsky M.N. Correction of oxidative damages during hepatic ischemia-reperfusion syn- drome. Zhurnal Grodnenskogo gosudarstvennogo meditsinskogo universiteta. 2016; 4(56): 20-25 (in Russ.)]

20. Шагидулин М.Ю., Онищенко Н.А., Крашенников М.Е. Трансплантация гепатоцитов как метод лечения печеночной недостаточности: экспериментальный и клинический опыт. Вестник трансплантологии и искусственных органов. 2010; 12(4): 53-60 [Shagidulin M.Y., Onishchenko N.A., Krasheninnikov M.E. Transplantation of hepatocytes as the method of treatment of liver failure: experimental and clinical experience. Russian journal of transplantology and artificial organs. 2010; 12(4): 53-60 (in Russ.)]

21. Donadon M., Molinari A.F., Corazzi F., Rocchi L., Zito P., Cimino M., Costa G., Raimondi F., Torzilli G. Pharmacological Modulation of Ischemic-Reperfusion Injury during Pringle Maneuver in Hepatic Surgery. A Prospective Randomized Pilot Study. World 7 Surg. 2016; 40(9):2202-2212.

DOI: $10.1007 / \mathrm{s} 00268-016-3506-1$.

22. Liu K.X., Kato Y., Matsumoto K. Characterization of the enhancing effect of protamine on the proliferative activity of hepatocyte growth factor in rat hepatocytes. Pharm Res. 2009; 26(4):1012-1021. DOI: $10.1007 / \mathrm{s} 11095-008-9810-1$.

23. Li J., Li R.J., Lv G.Y., Liu H.Q. The mechanisms and strategies to protect from hepatic ischemiareperfusion injury. Eur Rev Med Pharmacol Sci. 2015; 19(11): 2036-2047.

24. Manzini G., Kremer M., Houben P., Gondan M., Bechstein W.O., Becker T., Berlakovich G.A., Friess H., Guba M., Hohenberger W., Ijzermans J.N.M., Jonas S., Kalff J.C., Klar E., Klempnauer J., Lerut J., Lippert H., Lorf T., Nadalin S., Nashan B., Otto G., Paul A., Pirenne J., Pratschke J., Ringers J., Rogiers X., Schilling M.K., Seehofer D., Senninger N., Settmacher U., Stippel Karlheinz Tscheliessnigg D.L., Ysebaert D., Binder H., Schemmer P. Reperfusion of liver graft during transplantation: techniques used in transplant centres within Eurotransplant and meta-analysis of the literature. Transpl Int. 2013; 26(5): 508-516. DOI: $10.1111 /$ tri.12083.

25. Reiling J., Lockwood D.S.R., Simpson A.H., Campbell C.M., Bridle K., Santrampurwala N., Britton L.J., Crawford D.H.G., Dejong C.H.C., Fawcett J. Urea production during normothermic machine perfusion: Price of success? Liver Transpl. 2015; 21(5):700-703. DOI: $10.1002 /$ lt.24094.

26. Suyavaran A. Preconditioning methods in the management of hepatic ischemia reperfusion- induced injury: Update on molecular and future perspectives. Hepatol Res. 2017 Jan; 47(1): 31-48. DOI: $10.1111 /$ hepr.12706.

Поступила в редакцию 01.12.2018 Подписана в печать 21.03.2019

Для цитирования: Литвинова Е.С., Конопля А.И., Дудка В.Т. Эффективность белков аллогенных гепатоцитов в коррекции иммунометаболических нарушений при остром ишемическом поражении печени. Курский научно-практический вестник «Человек и его здоровье». 2019;(1):103-113. DOI: 10.21626/vestnik/2019-1/12. 


\title{
EFFECTIVENESS OF PROTEINS OF ALLOGENEIC HEPATOCYTES IN THE CORRECTION OF IMMUNOMETABOLIC DISORDERS IN ACUTE ISCHEMIC LIVER DAMAGE
}

\author{
๑ Litvinova E.S., Konoplya A.I., Dudka V.T.
}

Kursk State Medical University (KSMU)

3, K. Marx st., Kursk, Kursk region, 305041, Russian Federation

\begin{abstract}
Objective. The aim of the study was to establish the effectiveness of the culture fluid of allogeneic hepatocytes (CFAH) and proteins isolated from them in correcting metabolic and immune disorders in acute ischemic liver damage.

Material and methods. The study has been conducted on 105 healthy mature Wistar rats. Acute ischemic liver damage (AILD) was induced by cross clamping of the hepatoduodenal ligament for 20 minutes. Isolated allogeneic hepatocytes from newborn animals were used to prepare a culture fluid from which proteins were isolated. The culture fluid of allogeneic hepatocytes $(\mathrm{CFAH})$ and their proteins obtained were administered with the start of modeling acute liver ischemia five times (with a 24-hour interval) intraperitoneally to rats with AILD at the rate of $5 \mathrm{mg} / \mathrm{kg}$.

Results. Acute liver ischemia causes the development of biochemical syndromes of the liver damage (cytolysis, intraand extrahepatic cholestasis, toxic damage, insufficiency of synthetic processes) activates the processes of lipid peroxidation, disturbs intra-erythrocyte metabolism, and causes the development of oxidative stress and suppression of forming the adaptive and innate immunity. Introduction of CFAH, undivided CFAH proteins or CFAH proteins with molecular mass (MM) less than $130 \mathrm{kDa}$ to animals with AILD normalizes or corrects the studied biochemical and immunological parameters. CFAH proteins with MM more than $130 \mathrm{kDa}$ do not have such effects.

Conclusion. During the analysis of CFAH or CFAH proteins corrective activity on the dynamics of biochemical markers of AILD, formation of humoral and cellular immunity, impaired functional and metabolic activity of peripheral blood neutrophils, intraerythrocyte metabolism, activation of free radical oxidation, the following sequence has been established (according to increasing the effectiveness): the lack of this activity in CFAH proteins with MM more than $130 \mathrm{kDa}$; the presence of normalizing and correcting activity of: CFAH - CFAH undivided proteins - CFAH proteins less than $130 \mathrm{kDa}$.

Keywords: immunometabolic disorders; culture proteins of allogeneic hepatocytes; acute liver ischemia.

Litvinova Ekaterina S. - PhD in Medicine, Associate Professor of Department of Pathological Anatomy, KSMU, Kursk, Russian Federation. E-mail: kat roma@mail.ru (correspondence author)

Konoplya Alexander I. - DM, Professor, Honored Scientist of the Russian Federation, Head of Department of Biological Chemistry, KSMU, Kursk, Russian Federation. ORCID iD: 0000-0003-4748-8405. E-mail: konoplya51@mail.ru

Dudka Victor T. - PhD in Medicine, Associate Professor, Head of Department of Pathological Anatomy, KSMU, Kursk, Russian Federation. E-mail: dudkaviktor@rambler.ru
\end{abstract}

\section{CONFLICT OF INTEREST}

The authors declare the absence of obvious and potential conflicts of interest related to the publication of this article.

\section{SOURCE OF FINANCING}

The authors state that there is no funding for the study.
CONFORMITY WITH THE PRINCIPLES OF ETHICS

The study was approved by the Ethical Committee under Kursk state medical university (Protocol No. 9 of 09.11.2015).

Received 01.12.2018

Accepted 21.03.2019

For citation: Litvinova E.S., Konoplya A.I., Dudka V.T. Effectiveness of proteins of allogeneic hepatocytes in the correction of immunometabolic disorders in acute ischemic liver damage. Kurskiy nauchno-prakticheskiy vestnik "Chelovek $i$ ego zdorov'ye" = Kursk Scientific and Practical Bulletin "Man and His Health". 2019;(1):103-113. DOI: 10.21626/vestnik/2019-1/12. 